\title{
Genetic Optimal Micrositing of Wind Farms by Equilateral-Triangle Mesh
}

\author{
Jun Wang ${ }^{1}$, Xiaolan $\mathrm{Li}^{2}$ and Xing Zhang ${ }^{3}$ \\ ${ }^{1}$ Tongji University \\ ${ }^{2,3}$ Tsinghua University
}

China

\section{Introduction}

The micrositing problem designs the layout, i.e. the number of turbines and specific location of each one, for a given farm based on the information of the weather, terrain and landscape of the farm. It aims to capture the wind energy of a farm more effectively while satisfying the constrains on economical, social and environmental issues. The micrositing process, a challenging subject involving fluid dynamics and decision making, plays a crucial role in wind farm planning (Conover \& Davis, 1994).

In engineering practice, designers usually calculate the wind flow of a given wind farm by commercial software, and empirically determine the installation positions of turbines based on the flow field. The flow field usually does not include the influence of turbines on the deflexion of the original air flow, i.e. wake effects. However, as the wake effects are complicated and strongly coupled, they play a crucial role in wind farm micrositing. In academia, the micrositing problem with the consideration of turbine wake effects were studied for relative flat terrains. Patel (1999) suggested that wind turbines should be placed in rows $8 \sim 12$ rotor diameters apart in the windward direction, and $1.5 \sim 3$ rotor diameters apart in the crosswind direction. As wind profiles were not considered, the solution was still an "empirical" one. Mosetti et al. (1994), for the first time, applied genetic algorithms (GA) to solve the problem of wind farm micrositing in a systematical manner. Grady et al. (2005) improved Mosetti's work in terms of programming and computing, and obtained more reasonable results. Wan et al. (2009) introduced the Weibull function to describe the probability of wind speed distributions and employed turbine speed-power curves to estimate turbine power generation.

In Mosetti et al. (1994) and Grady et al. (2005), a square wind farm of $2 \mathrm{~km} \times 2 \mathrm{~km}$ was partitioned into $10 \times 10$ squares and the turbines could only be installed in the center of suitable small squares. The square mesh (SM) simplified and reformulated the micrositing problem into a discrete-time optimization one, which could be tackled by a binary-coded GA. Although SM is the most simple and instinctive choice, it is worthwhile investigating alternative, and probably better meshing methods. In this paper, a novel equilateral-triangle 
mesh (ETM) is presented, which proves to be a more suitable method in terms of wind farm production and energy efficiency.

The remainder of this paper is organized as follows. Section 2 introduces the methodology of the optimal micrositing problem. Section 3 carries out computational simulations and analyzes the results. Section 4 makes concluding remarks.

\section{Methodology}

In this section, the mathematical model of the optimal micrositing problem is firstly formulated, the equilateral-triangle mesh is then presented, and the genetic algorithm for the problem is introduced.

\subsection{Mathematical modeling}

The models of wake effects, cost and optimal objective functions in Mosetti et al. (1994) and Grady et al. (2005) are used in this paper for a fair comparison. For clarity and completeness, the models are briefly repeated in the following but with some new insights.

\subsubsection{Wake effects}

Jensen (1983) developed a simplified wake model, which neglected the near field behind a wind turbine. As illustrated in Figure 1, the wake has an initial diameter roughly equal to the turbine diameter and spreads linearly with the downwind distance.

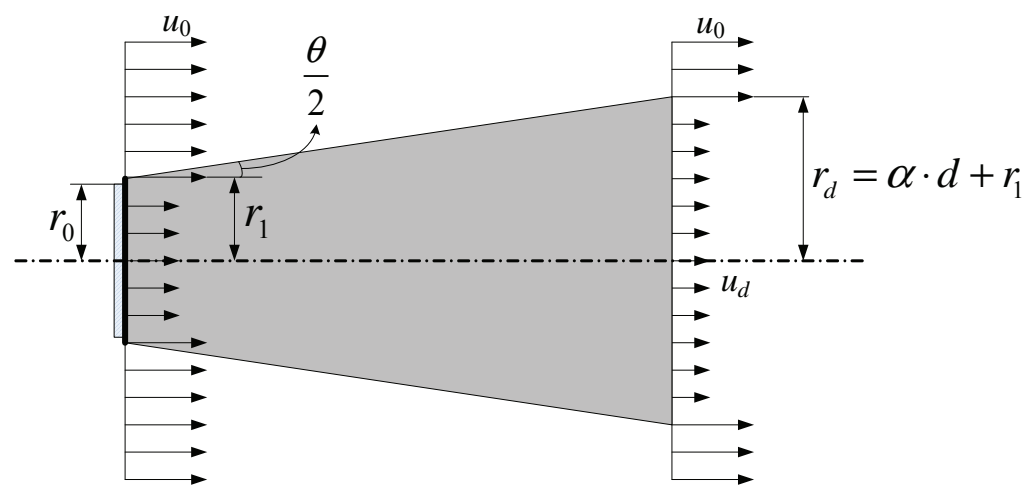

Fig. 1. Schematic view of wake effects (Jensen, 1983)

Based on the theorem of momentum balance, the wake velocity can be determined by the following expression

$$
u_{d}=u_{0}\left(1-\frac{2 a}{\left(1+\alpha \cdot d / r_{1}\right)^{2}}\right)
$$

where $r_{1}$ is the wake radius just behind the rotor, $a$ is the initial velocity deficit, and the other symbols are illustrated in Figure 1. Readers can refer to Grady et al. (2005) for the details. The entrainment constant $\alpha$ is empirically calculated by

$$
\alpha=\frac{0.5}{\ln \left(h / z_{0}\right)}
$$


where $h$ is the turbine hub height, and $z_{0}$ is the surface roughness. The divergence angle $\theta$, as indicated in Figure 1, is then defined as $\theta=2 \arctan \alpha$.

The relation between roughness lengths, terrain surface characteristics and roughness classes is given in the European Wind Atlas (Troen \& Petersen, 1989). The roughness length ranges from $0.0001 \mathrm{~m}$ to $1.00 \mathrm{~m}$, where $0.0001 \mathrm{~m}$ represents water areas and $1.00 \mathrm{~m}$ represents cities. Figure 2 shows the corresponding divergence angle $\theta$, under different roughness lengths and turbine hug heights, ranges roughly from $4^{\circ} \sim 15^{\circ}$.

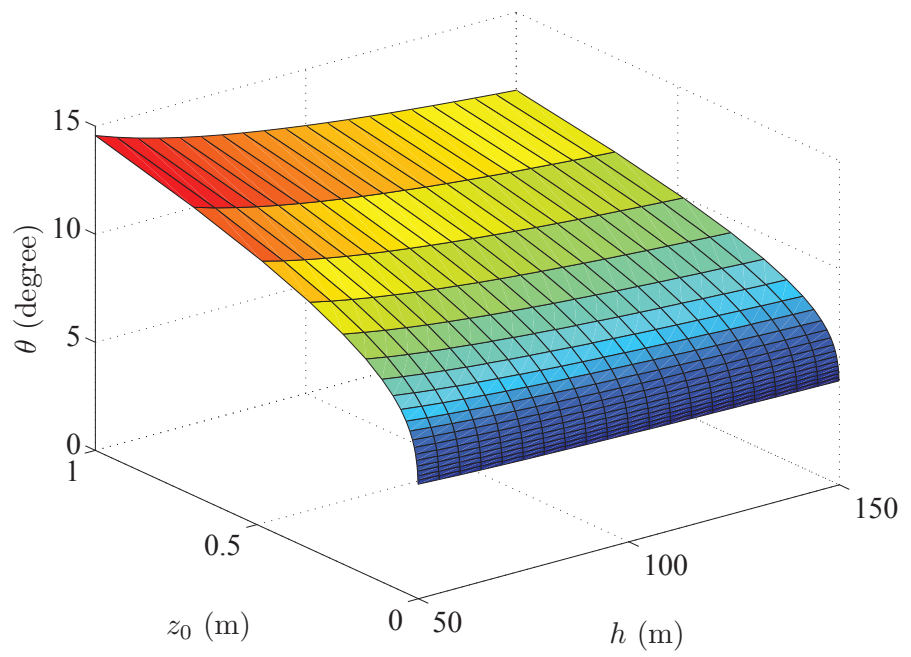

Fig. 2. Divergence angle

When multiple wakes overlap at the downstream turbines, Katic et al. (1986) assumed the kinetic energy deficit of a mixed wake to be equal to the sum of the energy deficits for each wake at the calculated position. So in the $i$ th wind direction, the downstream wind speed $u_{[i, j]}$ at the $j$ th turbine can be computed by (Kiranoudis et al., 2001)

$$
u_{[i, j]}=u_{0}-\sqrt{\sum_{k=1}^{N_{[i, j]}}\left(u_{[i, k]}-u_{[i, j, k]}\right)^{2}}
$$

where $u_{0}$ is the freedom wind speed, $N_{[i, j]}$ is the number of the turbines preceding the $j$ th one, and $u_{[i, j, k]}$ is the actual wind speed from the $k$ th turbine at the position of the $j$ th turbine.

\subsubsection{Objective function}

The optimal micrositing problem in this paper is to maximize energy production while minimizing project costs.

For a wind farm with $N$ turbines and the wind distributed among $M$ directions, the total output of the farm can be evaluated by (Grady et al., 2005; Kiranoudis et al., 2001)

$$
\mathcal{P}=0.3 \sum_{i=1}^{M}\left(p_{i} \sum_{j=1}^{N} u_{[i, j]}^{3}\right)
$$


where $p_{i}$ represents the annual frequency of the $i$ th wind direction.

Capital costs are one of the primary factors, which should be considered when determining optimum turbine spacing (Conover \& Davis, 1994). The Department for Business, Enterprise and Regulatory Reform (United Kingdom) carried out a study on the cost breakdown of a wind energy investment in Europe in 2007 (Department of Trade and Industry, 2007), which claimed that turbine ex works accounted for $66 \%$ of the capital cost. And the Spanish report from Intermoney-AEE claimed that $72 \%$ of the total costs is for the turbine ex works (Intermoney-AEE, 2006). In this paper, we follow Mosetti et al. (1994) and Grady et al. (2005) and only consider the investment on the wind turbines. The total cost per year of the whole wind farm project is (Grady et al., 2005; Mosetti et al., 1994)

$$
\mathcal{C}=N\left(\frac{2}{3}+\frac{1}{3} e^{-0.00174 N^{2}}\right)
$$

In conclusion, the objective function is to minimize the cost per unit energy, i.e. (Grady et al., 2005)

$$
\min \frac{\mathcal{C}}{\mathcal{P}}
$$

while guaranteeing the safe distance between any turbines.

\subsection{Equilateral-triangle mesh}

The micrositing problem defined above is a constrained optimal control one, which is rather technically challenging and computationally time-consuming due to the constraints on turbine distances. To tackle the problem, it is natural to reduce such a constrained problem into an unconstrained one.

To guarantee the minimal distance between any turbines, the most convenient way is to partition a wind farm into square cells of predefined width and to only allow turbines to be placed in the center of appropriate cells (Grady et al., 2005; Marmidis et al., 2008; Mosetti et al., 1994), as illustrated in Figure 3. The square meshing is simple and intuitive, and easy to implement. It guarantees any turbine in a farm is the same distance to adjacent ones in the same row or column if exist. However, the turbines in a diagonal direction will be unnecessarily spaced apart, i.e. the distance is magnified by $\sqrt{2}$, and therefore the wind farm is not fully exploited.

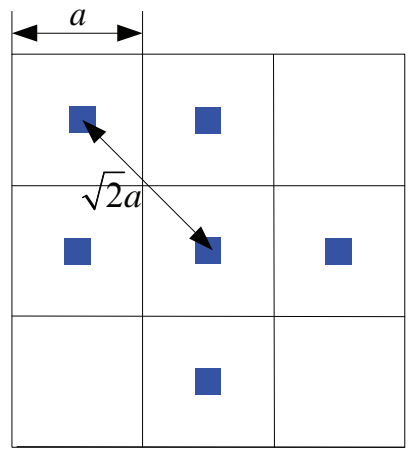

Fig. 3. An example of square meshing 
An intuitive idea is to locate the wind turbines at the center of some circular cells, which are tangent to each other as illustrated in Figure 4(a). When the centers of the cells are connected, we obtain intertwined equilateral hexagons shown in Figure 4(b), seemingly a "honeycomb" mesh. If further analyzed, the hexagons can be decomposed into six equilateral triangles and the triangle vertices represent the possible positions of turbines, as shown in Figure 4(c). Therefore, the mesh is called the equilateral-triangle mesh.

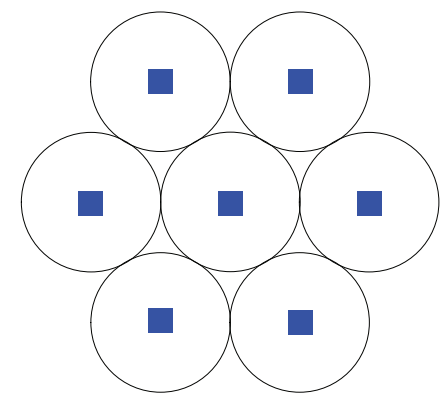

(a) Tangent circles

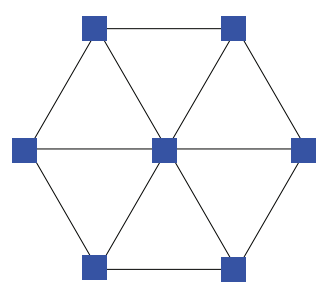

(b) Hexagons

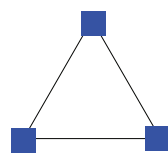

(c) Triangle

Fig. 4. Equilateral-triangle mesh

As recommended in Troen \& Petersen (1989), for a flat farm with unidirectional wind, turbines should be place about $3 \sim 5$ times of rotor diameter apart in columns and about $5 \sim 9$ times in rows. In this paper, we follow Mosetti et al. (1994), Grady et al. (2005) and Marmidis et al. (2008), and set the side length of the triangle as five times of the turbine rotor diameter.

Definition 1 (ETM orientation). Pick up any equilateral triangle in a mesh, construct a vector from the center of the triangle to the vertex and obtain the angle $\phi$ (in degrees) of this vector from the north-direction vector (i.e. y-axis) clockwise, as illustrated in Figure 5. The orientation of the mesh is defined as

$$
\psi=\bmod \left(\phi, 60^{\circ}\right)
$$

where mod stands for the modulo operation. For convenience, an ETM with an orientation angle $\psi$ is denoted as ETM- $\psi$.

Then, the orientation of the traditional SM can be similarly defined as follows.

Definition 2 (SM orientation). Pick up any square in the mesh, and construct a vector from the center of the square towards one of its vertices. The clockwise angle from the north-direction vector towards it is $\phi$ (in degrees). The orientation of the traditional SM is defined as

$$
\psi=\bmod \left(\phi, 90^{\circ}\right)
$$

Under this definition, the orientation of the square meshes used in Mosetti et al. (1994), Grady et al. (2005), and Marmidis et al. (2008) were $45^{\circ}$, which can be denoted as ETM- $45^{\circ}$ in short.

\subsection{Genetic algorithms}

Due to the complexity of the optimal micrositing, genetic algorithms are introduced to solve it. Unlike the traditional calculus-based methods, GAs are robust, global, and do not require 


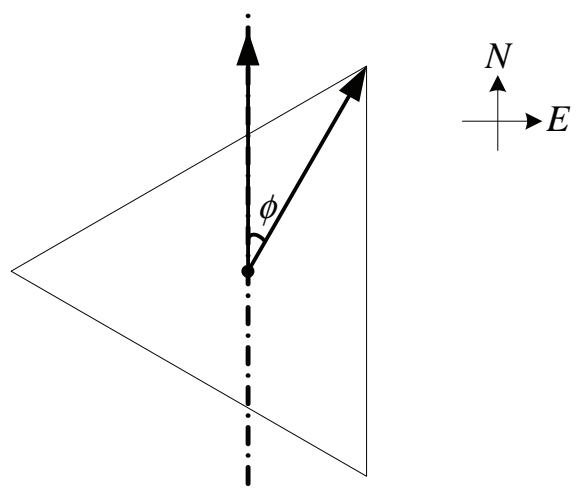

Fig. 5. Orientation of mesh

the existence of derivatives of objective functions. The basic procedures of the GA are as follows (Houck et al., 1995):

Step 1 Encode the micrositing problem into a binary string.

Step 2 Randomly generate a population representing a group of possible solutions.

Step 3 Calculate the fitness values for each individual.

Step 4 Select the individuals according to their fitness values.

Step 5 Perform crossover and mutation operations on the selected individuals to create a new generation.

Step 6 Check whether the progress is convergent, or meets the terminating condition. If not, return to Step 3.

Encoding is the first step of the GA procedures. Suppose a wind farm is a square region partitioned into equilateral-triangle cells, whose vertices represent the possible positions for placing turbines. Each bit corresponds to a vertex and all of the bits are connected serially into a binary string in a top-down left-right sequence. In the string, " 1 " represents that a turbine is placed on the corresponding vertex, while " 0 " stands for no wind turbine.

The selection, crossover and mutation are the fundamental operators of GAs. Generally, a probabilistic selection is performed based upon the individual's fitness such that the better individuals have an increased chance of being selected, and the probability is assigned to each individual based on its fitness value. The crossover takes two individuals and produces two new individuals while the mutation alters one individual to produce a single new solution (Houck et al., 1995). The crossover probability is usually between $0.6 \sim 0.9$, and the mutation probability between $0.01 \sim 0.1$ (Sivanandam \& Deepa, 2008). In this paper, the crossover probability is chosen to be 0.7 through trial-and-error processes, and the mutation probability 0.05 .

\section{Simulation results and analyses}

In this paper, the Genetic Algorithm Optimization Toolbox is utilized for simulations. The micrositing results of the ETM method are compared with the SM method employed by 
Mosetti et al. (1994) and Grady et al. (2005). For a fair comparison, the same turbines are utilized, i.e. turbines with the hub height $60 \mathrm{~m}$, the rotor radius $20 \mathrm{~m}$ and the thrust coefficient 0.88. The ground roughness length of the site is $z_{0}=0.3 \mathrm{~m}$, and the minimal-distance between wind turbines is $200 \mathrm{~m}$. Note that, due to the different mesh methods, the effective region for micrositing is $1800 \times 1800$ square meters in this paper while $2000 \times 2000$ square meters in Mosetti et al. (1994), Grady et al. (2005) and Marmidis et al. (2008).

The following three cases in Grady et al. (2005) are investigated and the wind rose map of Case 3 is given in Figure 6.

- Case 1: Single-direction wind with a speed of $12 \mathrm{~m} / \mathrm{s}$;

- Case 2: Multiple-direction (36 directions) wind with a speed of $12 \mathrm{~m} / \mathrm{s}$;

- Case 3: Multiple-direction (36 directions) wind with typical speeds of 8,12 and $17 \mathrm{~m} / \mathrm{s}$.

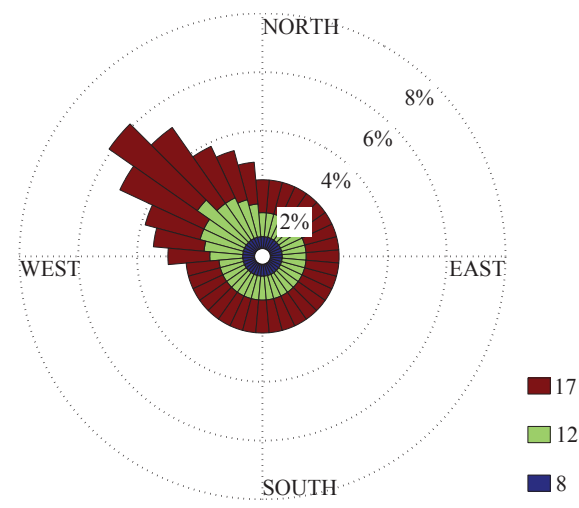

Fig. 6. Rose map of Case 3

\subsection{Case 1: Single-direction \& uniform-speed wind}

The optimal micrositing layouts by the ETM method are presented in Figure 7(c) and Figure 7(d) while the SM-based result in Grady et al. (2005) is shown in Figure 7(a). By using the ETM- $30^{\circ}$, turbines are roughly arranged in three evenly-spaced groups, which is similar to the layout by the SM method (Grady et al., 2005). Due to the nature of the ETM, the turbines in each group (two rows) are staggered, which is consistent with the "empirical" scheme. By using the ETM $-0^{\circ}$, turbines are arranged into two rows in the top of the farm and the other two in the bottom. Compared to the layout by the ETM- $30^{\circ}$, the turbines in each group are more closely placed. Note that, the ETM- $0^{\circ}$ is the same direction as the wind, while the ETM- $30^{\circ}$ is perpendicular to the wind direction. And what will happen if we chose a SM whose direction is perpendicular to the wind? The optimal layout of SM- $0^{\circ}$ is presented in Figure $7(\mathrm{~b})$.

Table 1 compares the fitness values, total power output and the numbers of wind turbines for each layout. It is clear that both ETM-based schemes achieve smaller fitness values. In particular, the fitness value of the ETM- $0^{\circ}$ layout is $7.89 \%$ lower than the ETM- $30^{\circ}, 5.74 \%$ 


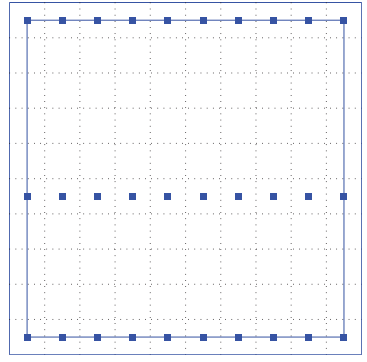

(a) $\mathrm{SM}-45^{\circ}$ (Grady's results)

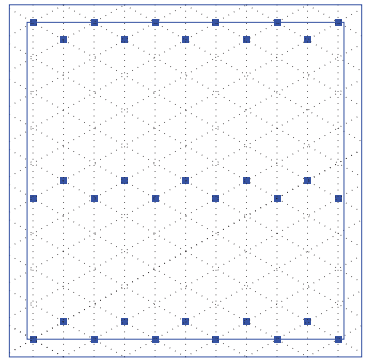

(c) $\mathrm{ETM}-30^{\circ}$

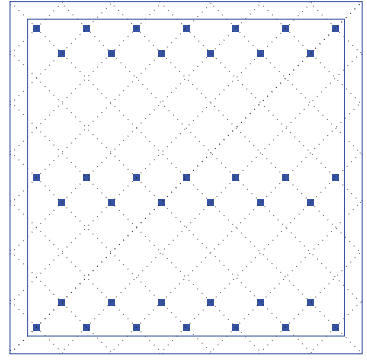

(b) $\mathrm{SM}-0^{\circ}$

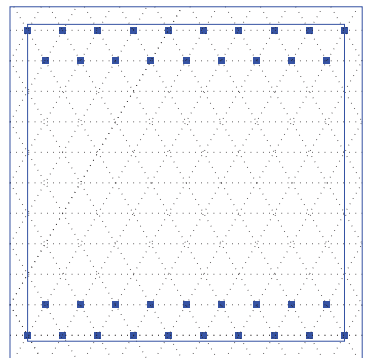

(d) $\mathrm{ETM}-0^{\circ}$

Fig. 7. Optimal micrositing layouts using different meshing methods (Case 1)

\begin{tabular}{cccc}
\hline Meshing Methods Fitness $\left(\times 10^{-3}\right)$ & Output $(\mathrm{kW})$ & WT Numbers \\
\hline SM-45 & & \\
SM-0 & 1.5436 & 14310 & 30 \\
ETM-30 $^{\circ}$ & 1.4809 & 18180 & 39 \\
ETM-0 $^{\circ}$ & 1.5152 & 15611 & 33 \\
\hline
\end{tabular}

Table 1. Results of ETM and SM-based optimal micrositing for Case 1

lower than the $\mathrm{SM}-0^{\circ}$ and $9.57 \%$ lower than the $\mathrm{SM}-45^{\circ}$. So the results prove the advantages of the ETM method over the traditional SM method.

Moreover, Table 1 also shows that the fitness values of the layouts are better when the mesh orientation is along the wind direction. It indicates that the performance can be further improved if the mesh orientation is appropriately chosen. In order to study how to choose the mesh orientation, several more simulations using different orientations of the ETMs are carried out, and their results are listed in Table. 2.

It is clear that the rotationally symmetrical ETM- $10^{\circ}$ and ETM- $50^{\circ}$ gain the best fitness. The layouts of these two orientations are presented in Figure 8. This is related to the divergence angle of the wind turbines. Since the wake effects decrease as the distance downstream of the turbine increases, we would prefer to place adjacent wind turbines outside of the region of wind turbine wakes. The divergence angle of the wind turbines determine the orientation 


\begin{tabular}{cccc}
\hline Meshing Methods Fitness $\left(\times 10^{-3}\right)$ & Output $(\mathrm{kW})$ & WT Numbers \\
\hline ETM-10 & 1.3727 & 21737 & 44 \\
ETM-20 & 1.3842 & 21556 & 44 \\
ETM-40 & 1.3832 & 22449 & 46 \\
ETM-50 & 1.3721 & 21746 & 44 \\
\hline
\end{tabular}

Table 2. Results of different orientations of ETMs for Case 1

of mesh based on their geometrical relationship. From Figure 2, we can observe that the divergence angle $\theta$ ranges roughly from $4^{\circ}$ to $15^{\circ}$. So the corresponding orientation angle $\phi$ of ETM should be better within $\left(\beta+\frac{\theta}{2}-30^{\circ}, \beta-\frac{\theta}{2}+30^{\circ}\right)$ to avoid wake effects, where $\beta$ is the dominant direction of the wind. Taking into account the side length of the triangle, we generally choose $\psi$ within

$$
\bmod \left(\beta \pm 10^{\circ}, 60^{\circ}\right)
$$

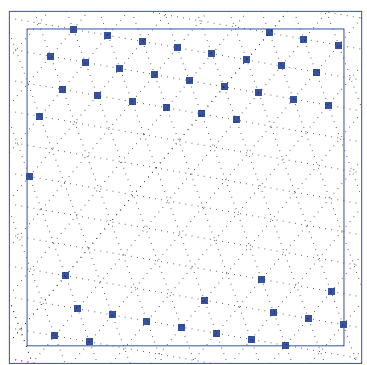

(a) $\mathrm{ETM}-10^{\circ}$

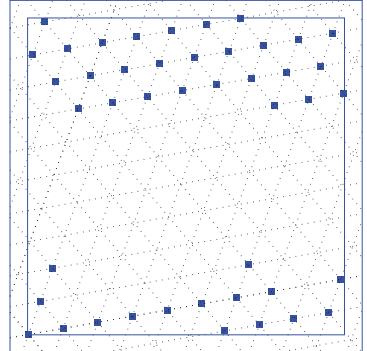

(b) $\mathrm{ETM}-50^{\circ}$

Fig. 8. Optimal micrositing layouts by using ETM-10 ${ }^{\circ}$ and ETM-50 ${ }^{\circ}$ (Case 1)

\subsection{Case 2: Multiple-direction \& uniform-speed wind}

In this case, the wind is evenly distributed in 36 directions and the wind speed in each direction is constant. Hence, the orientation of the ETM does not affect the micrositing and we choose ETM- $0^{\circ}$ in order to obtain the maximum number of mesh grid. Figure 9 (b) shows the optimal layout by using the ETM method. It is clear that the layout is 6-fold rotational symmetry, which is consistent with the 36 -fold rotational-symmetry rose map. The layout by the SM method, shown in Figure 9(a), is not as symmetrical as the ETM-based one, although it is evenly distributed in general.

Table 3 compares the micrositing results by both methods. The ETM-based layout produces $18256 \mathrm{~kW}$ with 39 wind turbines and its fitness value is $5.87 \%$ lower than Grady's. The efficiency of turbines, defined as the ratio of their actual power to the rated one, is improved by $6.02 \%$, from Grady's $85.174 \%$ to $90.299 \%$. The results indicate that the ETM method is more suitable for a farm with even distribution of wind directions.

\subsection{Case 3: Multiple-direction \& multiple-speed wind}

This case represents a more practical situation, where the wind is generally evenly distributed but slightly dominated in the north-west direction (about $310^{\circ}$ ) as one can observe from 


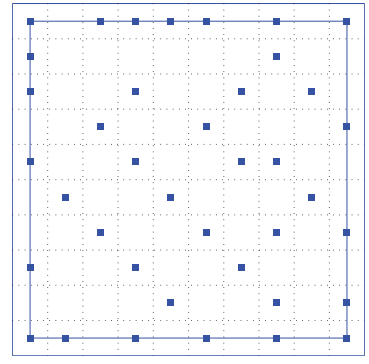

(a) Square mesh (Grady's results)

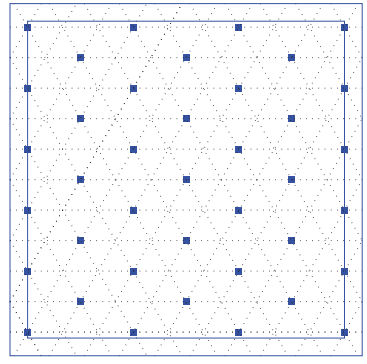

(b) ETM-0 $0^{\circ}$

Fig. 9. Optimal micrositing layouts using different meshing methods (Case 2)

\begin{tabular}{cccc}
\hline Meshing Methods Fitness $\left(\times 10^{-3}\right)$ & Output $(\mathrm{kW})$ & WT Numbers \\
\hline SM- $45^{\circ}$ & 1.5666 & 17220 & 39 \\
ETM-0 & 1.4746 & 18256 & 39 \\
\hline
\end{tabular}

Table 3. Results of different orientations of ETMs for Case 2

Figure 6. We choose an ETM with an orientation $10^{\circ}$ since $\bmod \left(310^{\circ}, 60^{\circ}\right)=10^{\circ}$. The optimal layouts by the SM method and the ETM one are presented in Figure 10.

Table 4 compares the present study with the Grady's, and proves that all of the ETM's fitness values are better than SM's. The fitness value of ETM- $0^{\circ}$ is decreased by $4.48 \%$, and the efficiency is increased by $4.23 \%$. The ETM- $40^{\circ}$ uses the same number of wind turbines as Grady's, but produces more power, gains a lower fitness value and a higher efficiency. Again, the selection of the ETM orientation agrees with the "thumb of rule" given in Equation (7). The ETM method is more suitable for wind farm micrositing than the SM one.

\begin{tabular}{|c|c|c|c|}
\hline Meshing Metl & ess $(\times 10$ & Output (k & $\mathrm{Nu}$ \\
\hline $\mathrm{SM}-45^{\circ}$ & $8.4240^{1}$ & 31958 & 39 \\
\hline ETM-0 ${ }^{\circ}$ & 8.0465 & 34164 & 40 \\
\hline ETM-10 & 8.2490 & 31957 & 38 \\
\hline ETM- $40^{\circ}$ & 8.2133 & 32779 & 39 \\
\hline
\end{tabular}

${ }^{1}$ Note that, for Case 3, the fitness value in Grady et al. (2005) is not consistent with its fitness curve. So we re-calculate the fitness value according to Grady's layout.

Table 4. Results of different orientations of ETMs for Case 3

\section{Conclusions}

This paper presented a novel meshing method, i.e. the equilateral-triangle mesh, for optimal micrositing of wind farms. The ETM method, compared with the traditional square mesh, guarantees the same distance between adjacent wind turbines and matches the empirical staggered-siting style. Computational simulations consistently illustrated the advantages of 


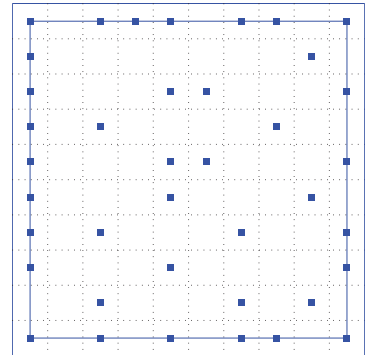

(a) $\mathrm{SM}-45^{\circ}$ (Grady's results)

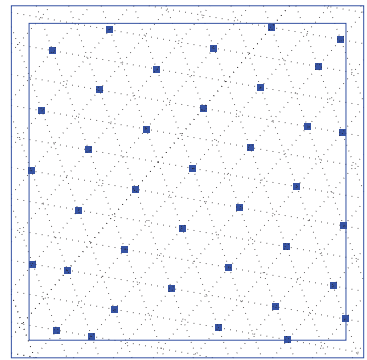

(c) ETM- $10^{\circ}$

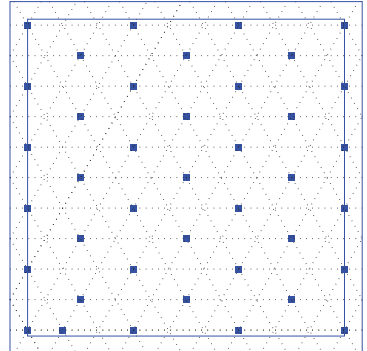

(b) ETM-0 $0^{\circ}$

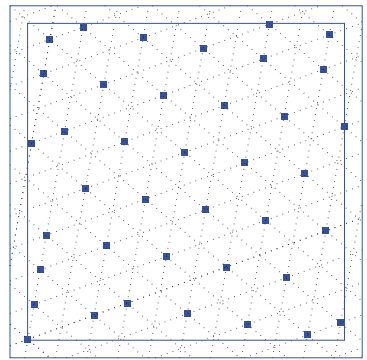

(d) $\mathrm{ETM}-40^{\circ}$

Fig. 10. Optimal micrositing layouts using different meshing methods (Case 3)

the ETM method especially when the orientation of the mesh was appropriately adjusted according to the dominant wind direction of a wind park.

\section{Acknowledgments}

This work was supported in part by the National High-Tech R\&D Program of China (863 Program) under Grant No. 2007AA05Z426, and the Natural Science Foundation of China under Grant No. 61075064.

\section{References}

Conover, K. \& Davis, E. (1994). Planning your first wind power project, Technical Report 104398, Electric Power Research Institute.

Department of Trade and Industry (2007). Impact of banding the renewables obligation costs of electricity production, Technical Report URN 07/948.

Grady, S. A., Hussaini, M. Y. \& Abdullah, M. M. (2005). Placement of wind turbines using genetic algorithms, Renewable Energy 30(2): 259-270.

Houck, C., Joines, J. \& Kay, M. (1995). A genetic algorithm for function optimization: A matlab implementation, Technical report, North Carolina State University. 
Intermoney-AEE (2006). Anaálisis y diagnóstico de la situación de la energía eólica en españa. Jensen, N. O. (1983). A note of wind generator interaction, Technical Report Risø-M-2411, Risø National Laboratory.

Katic, I., Hojstrup, J. \& Jensen, N. O. (1986). A simple model for cluster efficiency, European Wind Energy Association Conference and Exhibition, Rome, Italy, pp. 407-410.

Kiranoudis, C. T., Voros, N. G. \& Maroulis, Z. B. (2001). Short-cut design of wind farms, Energy Policy 29(7): 567-578.

Marmidis, G., Lazarou, S. \& Pyrgioti, E. (2008). Optimal placement of wind turbines in a wind park using monte carlo simulation, Renewable Energy 33(7): 1455-1460.

Mosetti, G., Poloni, C. \& Diviaccoa, B. (1994). Optimization of wind turbine positioning in large windfarms by means of a genetic algorithm, Journal of Wind Engineering and Industrial Aerodynamics 51(1): 105-116.

Patel, M. R. (1999). Wind and Power Solar Systems, CRC Press, Boca Raton, Florida.

Sivanandam, S. N. \& Deepa, S. N. (2008). Introduction to Genetic Algorithms, Springer, New York.

Troen, I. \& Petersen, E. L. (1989). European Wind Atlas, Risø National Laboratory, Roskilde.

Wan, C.-Q., Wang, J., Yang, G., Li, X.-L. \& Zhang, X. (2009). Optimal micro-siting of wind turbines by genetic algorithms based on improved wind and turbine models, Proceedings of the IEEE Conference on Decision and Control, Shanghai, P.R. China, pp. 5092-5096. 


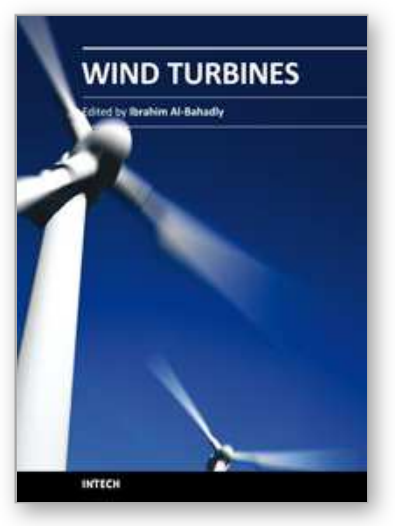

\author{
Wind Turbines \\ Edited by Dr. Ibrahim Al-Bahadly
}

ISBN 978-953-307-221-0

Hard cover, 652 pages

Publisher InTech

Published online 04, April, 2011

Published in print edition April, 2011

The area of wind energy is a rapidly evolving field and an intensive research and development has taken place in the last few years. Therefore, this book aims to provide an up-to-date comprehensive overview of the current status in the field to the research community. The research works presented in this book are divided into three main groups. The first group deals with the different types and design of the wind mills aiming for efficient, reliable and cost effective solutions. The second group deals with works tackling the use of different types of generators for wind energy. The third group is focusing on improvement in the area of control. Each chapter of the book offers detailed information on the related area of its research with the main objectives of the works carried out as well as providing a comprehensive list of references which should provide a rich platform of research to the field.

\title{
How to reference
}

In order to correctly reference this scholarly work, feel free to copy and paste the following:

Jun Wang, Xiaolan Li and Xing Zhang (2011). Genetic Optimal Micrositing of Wind Farms by EquilateralTriangle Mesh, Wind Turbines, Dr. Ibrahim Al-Bahadly (Ed.), ISBN: 978-953-307-221-0, InTech, Available from: http://www.intechopen.com/books/wind-turbines/genetic-optimal-micrositing-of-wind-farms-byequilateral-triangle-mesh

\section{INTECH}

open science | open minds

\author{
InTech Europe \\ University Campus STeP Ri \\ Slavka Krautzeka 83/A \\ 51000 Rijeka, Croatia \\ Phone: +385 (51) 770447 \\ Fax: +385 (51) 686166 \\ www.intechopen.com
}

\author{
InTech China \\ Unit 405, Office Block, Hotel Equatorial Shanghai \\ No.65, Yan An Road (West), Shanghai, 200040, China \\ 中国上海市延安西路65号上海国际贵都大饭店办公楼405单元 \\ Phone: +86-21-62489820 \\ Fax: +86-21-62489821
}


(C) 2011 The Author(s). Licensee IntechOpen. This chapter is distributed under the terms of the Creative Commons Attribution-NonCommercialShareAlike-3.0 License, which permits use, distribution and reproduction for non-commercial purposes, provided the original is properly cited and derivative works building on this content are distributed under the same license. 